\title{
Work-Life Balance Practices in Nigeria: A Comparison of Three Sectors
}

\author{
- Ojo Ibiyinka Stella, Salau Odunayo Paul, Falola Hezekiah Olubusayo
}

\begin{abstract}
The study investigates the concept of work-life balance (WLB) policies and practices in three sectors of the Nigerian Economy namely the Banking, Educational and Power Sector. The types of WLB initiatives available in the three sectors were explored and the barriers to implementation of the WLB initiatives were identified. This research implored quantitative methods to investigate the work-life balance practices in three sectors of the Nigerian Economy. This was achieved using an in-depth case study analysis of these sectors. The data set comprised of responses from both managers and employees in the Banking sector with five hundred and eighty six copies of the questionnaire retrieved. The Educational sector comprised of both managers and employees with five hundred and thirty one copies of the questionnaire retrieved; while five hundred and seven copies retrieved from the Power Sector. The findings reveal that there is diversity in terms of how respondents perceive the concept of Work-Life Balance. There is a wide gap between corporate WLB practices and employees' understanding of the concept; the paper suggests some policy implications which would aid the implementation of WLB policies in the studied sectors. This study also suggests direction for future research.
\end{abstract}

Keywords: work life balance, Nigerian banking sector, Educationalsector, Powersector, Human resource management. JEL Classification: M12

\section{INTRODUCTION}

Work life balance is an area of increasing importance to both employees and employers. Employees need it to balance work and non-work roles and employers require it to increase productively and reduce cost (Abbott \& De Cieri, 2008). The drivers for WLB can be attributed to changes in the demographic distribution of the labour force, technological advancement and the 24/7 opening hour's culture in Morden society (Beauregard \& Henry, 2009; Kalliath \& Brough, 2008). While there is no consistent definition of work-life balance, there are some consistent themes which have emerged these include: employees achieving an acceptable balance between their work and personal lives, employers work initiative which would aid improve employees productivity providing a range of targeted work-life initiatives that enhance firm performance and not result into considerable increase in cost to the employers (De Cieri,Holmes, Abbott \& Pettit, 2005; De Cieri \& Bardoel, 2009).

For the purposes of this study the definition of WLB proposed by Barrera (2007) would be adopted because it is broad and encompassing "Employers working constructively with their employees to put in place arrangements, which take into account the needs of the business as well as the non-work aspects of employees' lives" (Barrera, 2007:2). The definition consist of both 
employees and employers who are both central to the subsequent use and successful implementation of WLB policies and practices and acknowledges that WLB can only be achieved as a joint effort between employers and employees. A review of the work-life literature reveals that WLB initiatives can be broadly divided into four dominant categories which include flexible working arrangement (home working, compressed hours); leave arrangement (Study leave, Parental leave); dependent care assistance (Child care arrangements and Crèche) and general services (Employment assistant programs) (De Cieri et al., 2005).

WLB research has greatly advanced in western countries (Ozbilgin, Beauregard, Tatli and Bell, 2011) however this cannot be said for developing economies like Nigeria where little is known about WLB practices, both in structural and cultural forms, and of course an obvious paucity of empirical studies in this area. This paper investigates the work-life balance (WLB) policies and practice in the three sectors of the Nigerian economy namely Banking, Educational and Power Sector. The study examines the understanding and benefits for the implication in these sectors so that they can be used to inform changes to organisational policy and practice hereby improving the wellbeing of the employee and organisational efficiency and productivity.

\subsection{Background of Study}

One of the inhibiting factors which must be acknowledged in the discussion of WLB is the relative scarcity of theory; this can be attributed to the fact that WLB is one of those areas of HRM where practice is ahead of theory (Brewster, 1998:256). Work-Life Balance is an area which has been flooded in western literature however far less attention has been given to the area in developing economies like Nigeria (Mordi, Mmieh \& Ojo, 2012). However, Mordi, Mmieh and Ojo (2012) acknowledged that some aspects of WLB practices may be less applicable or require substantial adaptation in Nigeria because of institutional and cultural differences. It is important for organizations to ensure that their employees have a satisfactory level of balance between work and other sphere of their life in order to ensure they maintain a high level of job quality so as to minimise errors which would be costly to the organisation which is referred to as the business case work-life balance (Forsyth \& Polzer-Debruyne 2007; Kossek \& Lambert 2005).

\subsection{Theoretical Underpinning}

One of the inhibiting factors which must be acknowledged in the discussion of WLB is the relative scarcity of theory; this can be attributed to the fact that WLB is one of those areas of HRM where practice is ahead of theory (Brewster, 1998:256). Several factors have identified by various researchers on the factors which affected employees work life balance some of the more prominent factors include work life conflict, workloads and Weekend work and irregular hours (Frone 2003; Maertz, Pearson \& Keough, 2003 \& Lingard \& Francis, 2004). WLB has many strands of thought just like many human resource topics. One school of thought stems from the work-life conflicts (WLC), which can be described as workers experiencing difficulty in finding a balance between work responsibilities and other multiple roles they can be engaged in such as being a spouse or a parent or being actively involved in voluntary activities, leisure activities, religious activities etc. WLB aims at minimising the amount of WLC experienced by workers (Forrest, Wardell and Sawyer, 2011). Forrest et al. (2011) are of the opinion that WLC are a result- 
ant effect of imbalance between work and other areas of the employees' lives. Work life balance aims at reducing the levels of WLC of employees hence ensuring that the employees have a more positive experience at their work place. Although the concept of WLB recognises that participation in multiple roles can have a positive effect on employees achieving promotion however, its negative effect is more predominate as previous research in the banking industry indicates that many employees in the sector suffer from work-life conflict as a result (Malik \& Khalid, 2008). Work-life conflict has increased due to role overload in the last decades which results in low job satisfaction, negative impact on job performance and increase the cost on organizations (Higgins \& Duxbury, 2003; De Cieri, Holmes, Abbott \& Pettit, 2005).

\section{NIGERIA'S CULTURAL, SOCIO-ECONOMIC AND LEGAL FRAMEWORK}

The Federal Republic of Nigeria is a West African country made up of 36 States and a Federal Capital Territory. The capital tertiary is Abuja; however, Lagos remains the largest commercial nerve centre of the country. The official language is English. Estimates for 2009 place the population at 167 million and the work force at 47.33 million (CIA, 2011). Nigeria is a diverse society with over 250 ethnic groupings and more than 400 dialects. Nigeria is a collectivist society and there is strong loyalty to individual who are either family members or from the same ethnic group. Nigeria is a strongly male-dominated society where gendered division of work prevail (Aluko, 2009).

Nigeria has been greatly influenced by the British system. The provisions of the Nigerian Labour Act (1974) concern mainly blue-collar workers and are very basic with limited government regulations for employers.

Daily hours of work are to be fixed by mutual agreement or by collective bargaining (section 13:1). Provision is made for rest intervals of no less than one hour in total if the day's work is longer than 6 hours (section 13,3), and for one day's rest per week (section 13:7). After twelve months of continuous service, a worker is entitled to an annual leave of at least six working days that may not be deferred by more than twelve months (section 18). Women are entitled to twelve weeks' maternity leave with at least half pay but usually the customary benefits are more generous with maternity leave fully paid. The ethnic groups are often distinguishable by geographical location, languages, and specific cultural traits although many socio-cultural traits are similar. Religion has had a considerable influence on many aspects of the indigenous cultures, including approaches to education Islam, Christianity and African traditional religions are the dominant religions in the country.

\section{COMPARATIVE CASE STUDIES ON THREE SECTORS OF THE NIGERIAN ECONOMY}

The HR Directors of selected organisation were contacted and their consent obtained only on the condition that they remain anonymous. 


\subsection{The Educational Sector}

The Nigerian Educational Sector Comprises of Seven Subsectors Early Childhood Care and Education, Non-Formal Education, Primary Education, Secondary Education, Teacher Education, Demand and Supply, Technical and Vocational Education and Higher Education. However for the purpose of this study the higher educational sector was chosen because it is more structured and has a stronger union representation who addresses workers welfare which is what WLB practices are centred around. Unions became active in the Nigerian institutions of higher learning in the 1970s; although some researchers argued that the unions have been present as early as the 1950s (Jega, 1996). Unionism in the tertiary institutions became reinforced between (1976-1979) under the then president Obasanjo who conducted a restructuring of the Nigerian Labour movement, and especially when it issued decrees which recognised the existence of the trade unions in these institutions in 1978 (Jega, 1996).

Another key characteristic influencing work life balance is the weak collective employee voice. Within the Nigerian academic environment, the lecturers are represented by a body called Academic Staff Union of Universities (ASUU). The national trade union - the Nigerian Labour Congress, which represents all workers in the country, has had to intervene in strengthening the bargaining power. Each of the unions in the tertiary institutions has played significant and dramatic roles which are generally positive in advancing growth and development of the Nigerian Universities. Also there has been a tremendous increase in the number of universities in the last five years with over a hundred private, State and Federal Universities. The massive expansion in the educational institutions has led academic staff members to also take up administrative responsibilities which resulted in increased work load (NUC, 2009). Unions have emerged to improve the conditions of service and work load. The unions also provide a platform for an effective articulation of grievances, a protection and defence of the basic rights of its members (Jega, 1996). The Lecturers have annual leave of up to 30 working days that can be split as convenient there is provision for medical leave and compassionate leave.

\subsection{The Banking Sector}

The Nigerian banking institution which began in 1892 has undergone radical transformation (Central Bank of Nigeria (CBN), 2011). The central bank of Nigeria sought to reposition Nigerian banks to attain a sound financial environment after the collapse of several banks in the 1990's. By the end of 2005, Nigeria's 89 banks were directed to recapitalize from 2 billion naira to a minimum of 25 billion naira (Asikhia 2010). This led to a consolidation of the Nigerian banking institutions through mergers and acquisitions (M\&A) and a whittling down of the Nigerian banks from 89 banks to 24 (Sanusi 2011). The number of bank branches has increased from 3,247 in 2003 to over 5,837 in 2010 and employment in the sector rose from 50,586 in 2005 to 71,876 in 2010 (Sanusi 2011). The Nigerian Banking sector is notorious for its long hour culture and high work load of employees in the sector (Epie, 2011) which results in neglect of other areas of life with parents not spending enough time with their children and many kids been raised by maids. This long hour culture has also resulted in many couples separating or divorcing. This trend has a negative influence on the Individuals because Nigeria is family oriented (traditional society) hence the failure of a family system is termed as a failure on the individuals part which tends to affect the success of persons. 


\subsection{The Power Sector}

This sector began operations in the early 1970's and has undergone series of changes. Nigeria has plans to increase access to electricity throughout the country. This may be due to operational inadequacies and inability of units to operate at full capacities of the generating stations and their respective percentage contributions to the total power products. Power sector the challenges in the power sector are numerous and can be broadly classified into four categories: Economic and social, Technical, Political and Environmental. Over the years the government plumped a lot of money into this sector however it has still be submerged in inadequacy and backwardness hence power reform was introduced in 2007 (Okoro and Chikuni, 2007). Although, there is a trade union in the sector which caters for the welfare of its employees; the sector still has its fair share of causal worker. The power sector has recently undergone privatisation hence there has been change in management style and variation in the work patterns with some of the employees doing early shift and others working late shift which has resulted in some of the employees experiencing WLC. This sector is vital to the growth of the country hence the need find out how the experiences of the employees of this sector can be improved by studying their WLB policies and practices.

\section{METHODOLOGY}

\subsection{Method}

Three sectors from the Nigerian economy were selected for the comparative study. The banking sector comprises of fifteen banks, the educational sector comprises of twenty two universities and the power sector the major power production company of the country. Comparisons are made between organisations which claim to have various work life initiatives. The study relies on a case study method. This is in view of the fact that WLB is a relatively new concept in employment structure and culture in Nigerian Labour market, the research strategy must be one that allows a researcher gain a greater understanding of the phenomenon under investigation (Saunder et al., 2009). A case study is a useful approach of enquiry as it affords a researcher an opportunity to comprehensively explore the motivations, meanings, experiences and implications attached to daily 'events, activities or processes of one or more individuals (Creswell 2009:13). Case studies are principally suitable when the margins between the phenomenon being studied and its environment are blurred (Yin 2003; Stake, 1995). In addition, case studies are useful in highlighting the importance of key research questions, clarifying concepts and theories (Easterby-Smith et al., 2008). Therefore this study has found case study most suitable to explore the managers and employees' experience of work-life balance in Banking, Educational and Power sectors.

\subsection{Research questions}

RQ 1: Which WLB initiatives are available in the Banking, Educational and the Power Sectors of Nigeria?

RQ 2: To what extent are managers and employees using the work life balance initiatives available in their organisations?

RQ 3: What are the barriers to implementation and maintenance of these WLB initiatives? 


\subsection{Data analysis}

In the study, questionnaires were administered. The questionnaire was adapted from Hooker et al. (2007) study on work life balance studies. The questionnaire was divided into four major sections, which covered the demographic characteristics of the respondents; the WLB initiatives available; the usage of WLB initiatives; and the factors influencing WLB implementation. The participants were solicited through a combination of e-mail, existing personal contacts and referrals and snowball. An initial pilot study was conducted to determine the reliability and validity of the research instrument. A total of one hundred and one, one hundred and twenty three and one hundred and fifteen respondents were surveyed during pilot run from the banking, educational and power sectors respectively. The questionnaire was considered fit for the study and conversely Seven hundred and fifty questionnaires each were distributed to both managers and employees in the banking, educational and power sectors concurrently. The data set comprised of responses from both managers and Employees in the Banking sector with five hundred and eighty six questionnaire survey retrieved. The Educational sector comprised of both managers and employees with five hundred and thirty one questionnaire survey retrieved five hundred and seven questionnaire survey retrieved from the Power Sector. All the employees was conducted by convenience method of non-probability sampling method with the main intention of eliciting information on three main constructs which include WLB initiative available, usage of the initiative and barriers to its implementation. To ensure anonymity and confidentiality individual companies were not identified.

This represents $78.1 \%, 70.8 \%$ and $67.6 \%$ response rate consecutively from the Banking, Educational and Power sectors which are significantly higher when compared to the previous studies of this nature (De Cieri, Holmes, Abbott \& Pettit, 2005; Kelliher \& Anderson, 2008). SPSS software package was used for the analysis of the questionnaire; t-tests were used for comparisons of means on independent samples and to check differences in WLB initiatives between the sectors. The WLB practices recorded significant Cronbach's alpha of $0.82,0.76$ and 0.86 respectively. Also the validity test procedure reported that each item of the scale for the three constructs record high loading factors $(\geq 0.3)$. The next section provides the findings of this study.

\section{FINDINGS}

\subsection{Demographic characteristics of the respondents}

Table 1 shows the demographic characteristics of the respondents from survey. Table 1 reveals that the respondents were representative of the varied demography of employee and managers of the three sectors. The power sector is a male-dominated sector, although it has improved very much in the last few years women are still few, mostly in administrative section. While the educational sector and banking sectors have an almost equal distribution of male and female employees. There is a general believe that WLB policies and practices are inclined towards female with more initiatives available for women such as maternity leave, childcare arrangements, parental leave. This is however not the case as there are paternity leave available to men, both childcare arrangements and parental leave can be used by male employees as well as more men now care for their children. 
Tab. 1 - Demographic characteristics of participants. Source: Field Survey, (2011).

\begin{tabular}{|c|c|c|c|}
\hline Characteristics & $\begin{array}{c}\text { Banking Sector } \\
(\%) \\
N=586\end{array}$ & $\begin{array}{c}\text { Educational Sector } \\
\qquad \begin{array}{c}(\%) \\
\mathrm{N}=531\end{array}\end{array}$ & $\begin{array}{c}\text { Power Sector } \\
\qquad \begin{array}{c}(\%) \\
\mathrm{N}=507\end{array}\end{array}$ \\
\hline \multicolumn{4}{|l|}{ Gender: } \\
\hline Male: & $42(246)$ & $47(250)$ & $74(375)$ \\
\hline Female: & $58(340)$ & $53(281)$ & $26(132)$ \\
\hline \multicolumn{4}{|l|}{ Marital Status: } \\
\hline Single: & $38(222)$ & $28(149)$ & $34(173)$ \\
\hline Married: & $48(281)$ & $59(313)$ & $58(294)$ \\
\hline Divorced: & $8(47)$ & $7(37)$ & $2(10)$ \\
\hline Widowed: & $3(18)$ & $2(11)$ & $3(15)$ \\
\hline Separated: & $3(18)$ & $4(21)$ & $3(15)$ \\
\hline \multicolumn{4}{|l|}{ Age: } \\
\hline Less Than 30: & $5(29)$ & $2(11)$ & $8(41)$ \\
\hline 31-40: & $59(346)$ & $3(16)$ & $39(198)$ \\
\hline 41-50: & $25(146)$ & $18(96)$ & $31(157)$ \\
\hline 51-60: & $10(59)$ & $37(196)$ & $18(91)$ \\
\hline Above 60: & $1(6)$ & $40(212)$ & $4(20)$ \\
\hline \multicolumn{4}{|l|}{ Position: } \\
\hline Senior Management: & $2(12)$ & $3(16)$ & $5(25)$ \\
\hline Middle Manager: & $16(94)$ & $18(96)$ & $18(91)$ \\
\hline Team Leader/ Supervisor: & $31(181)$ & $37(196)$ & $25(127)$ \\
\hline Employee: & $51(299)$ & $42(223)$ & $52(264)$ \\
\hline \multicolumn{4}{|l|}{ Length In Employment: } \\
\hline 1-5: & $9(53)$ & $4(21)$ & $12(61)$ \\
\hline 6-10: & $24(140)$ & $20(106)$ & $30(152)$ \\
\hline 11-15: & $35(205)$ & $33(175)$ & $21(106)$ \\
\hline 16-20: & $23(135)$ & $31(165)$ & $22(112)$ \\
\hline Above 21: & $9(53)$ & $12(64)$ & $15(76)$ \\
\hline
\end{tabular}

The survey focused on identifying which WLB practices were available in the banking, educational and power sector of the Nigerian economy which are identified in table 2. 
Tab. 2 - WLB initiatives. Source: Field Survey, (2011).

\begin{tabular}{|l|c|c|c|}
\hline \multicolumn{1}{|c|}{ WLB initiatives } & Banking sector & Educational Sector & Power Sector \\
\hline Full time & Available & Available & Available \\
\hline Part time & Not Available & Available & Available \\
\hline Flexitime & Available & Available & Not Available \\
\hline Term time & Not Available & Available & Not Available \\
\hline Home working & Available & Available & Not Available \\
\hline Study leave & Available & Available & Available \\
\hline $\begin{array}{l}\text { Parental leave } \\
\text { (care for sick dependent) }\end{array}$ & Available & Available & Available \\
\hline Maternity leave & Available & Available & Available \\
\hline Paternity leave & Available & Not Available & Not Available \\
\hline Childcare arrangements (crèche) & Available & Available & Available \\
\hline
\end{tabular}

Table 2 shows the WLB practices which were available in the three sectors of the economy these initiatives majority of the WLB initiatives which can be identified in western literature with the exception of some practices such as Job share, annualised hours and compressed hours which were understandably unavailable since workers collectively have a preference for the conventional full time permanent contracts to temporary or casual work. The respondents were asked to identify which WLB practices were available to them by responding to a sixteen-item scale developed for this study $(1=$ no; $2=$ yes). The respondents were then asked to indicate the percentage of the usage of these policies. Barriers to WLB were then explored using a eight-item scale measuring constraints to the effective implementation of the WLB practices. Items included increase work demands, long hour culture and lack of support from line managers. A five- point Likert scale was utilized with responses from 1 (Strongly disagree) to 5 (Strongly agree).

\section{RESULTS AND DISCUSSION}

The first research question identified the various WLB initiatives which were available in banking, educational and power sector shown in table 2 and the percentage of its usage is represented in table 3 below which addresses the second research question.

Tab. 3 - Percentage of usage of WLB initiatives across sectors. Source: Field Survey, (2011).

\begin{tabular}{|l|c|c|c|}
\hline WLB initiatives & $\begin{array}{c}\text { Banking } \\
\text { Sector } \%\end{array}$ & $\begin{array}{c}\text { Educational } \\
\text { Sector } \%\end{array}$ & $\begin{array}{c}\text { Power } \\
\text { Sector } \%\end{array}$ \\
\hline Full time & 100 & 91 & 93 \\
\hline Part time & 0 & 9 & 7 \\
\hline Flexitime & 6 & 35 & 0 \\
\hline Term time & 0 & 37 & 0 \\
\hline
\end{tabular}




\begin{tabular}{|l|c|c|c|}
\hline Home working & 4 & 17 & 0 \\
\hline Study leave & 31 & 59 & 26 \\
\hline Parental leave (care for sick dependent) & 41 & 32 & 29 \\
\hline Maternity leave & 27 & 26 & 19 \\
\hline Paternity leave & 2 & 0 & 0 \\
\hline Childcare arrangements (crèche) & 42 & 34 & 42 \\
\hline
\end{tabular}

The percentage of usage was reflective of national culture which chooses full time work because surplus of labour which exist in the country. Study leave was unsurprisingly high in the educational sector because most of the academic staff had to improve themselves to stay relevant in the field. The childcare arrangements and parental leave were more popular across the three sectors because they were indicated as the most common form of arrangement. The respondent were also asked to indicate whether the initiatives were available to a specific group of employees and the respondents in the banking sector indicated that flexitime and home working were usually undertaken by the managers. While employees in the educational sector indicated that home working was usually suited for managers. In the educational sector and power sector, mothers can obtain extended maternity leave with the guarantee of returning to their previous position which is not the case in the Banking sector. Paternity leave has been introduced in a few of the banks while there no such leave arrangement in the educational and power sectors.

The educational sector has a wide range of policies to allow for time flexibility. The Banking sector and power sector, by contrast, has no special policy with regard to work-life balance beyond what is strictly required by the law. There is flexibility in taking annual leave or short vacations, but this is a general practice in the Nigerian society rather than a deliberate policy.

Correlation analysis was used to examine the relationship between the implementation of WLB initiative and its actual usage. The results revealed that the more WLB practices available in a sector, the more likely its usage $(\mathrm{r}=.351, \mathrm{p}<0.001)$. However, comparing employee usage with the amount of WLB initiative implemented in the sector, the findings overall suggest that employee usage lags behind the implementation of WLB initiative; there appears to be some delay between a sectors effort to introduce WLB initiatives and managers and employees taking up the opportunity to using the available WLB initiatives. These findings are consistent with those of De Cieri, Holmes, Abbott, Pettit (2005); Kirby and Krone (2002); De Cieri, Holmes, Abbott, \& Pettit, (2002) who found that an organisational culture that is unsupportive of WLB initiatives may lead to managers and employees reluctance to utilise those initiatives.

Several factors have been indicated from western literature as major constraints to the implementation of WLB initiatives some of which were tested out in the three sectors of the Nigerian economy. Research question 3 which is the barriers to implementing and maintaining WLB initiatives are addressed by table 4 . 
Tab. 4 - Barriers to WLB initiatives. Source: Field Survey, (2011).

\begin{tabular}{|l|c|c|c|}
\hline \multicolumn{1}{|c|}{ Barriers } & $\begin{array}{c}\text { Banking sector } \\
\text { mean }\end{array}$ & $\begin{array}{c}\text { Educational Sector } \\
\text { mean }\end{array}$ & $\begin{array}{c}\text { Power Sector } \\
\text { mean }\end{array}$ \\
\hline Increase job demands & 4.12 & 4.31 & 4.24 \\
\hline $\begin{array}{l}\text { Long Hour culture and irregular } \\
\text { work hours }\end{array}$ & 4.11 & 4.01 & 4.09 \\
\hline Lack of managerial support & 4.16 & 4.34 & 4.07 \\
\hline Inability to achieve flexible working & 4.25 & 4.19 & 4.26 \\
\hline Ineffective implementation strategy & 4.32 & 4.16 & 4.32 \\
\hline $\begin{array}{l}\text { Lack of Communication from top } \\
\text { down i.e. senior management to } \\
\text { employee }\end{array}$ & 4.45 & 4.38 & 4.15 \\
\hline $\begin{array}{l}\text { Failure to evaluate impact of initia- } \\
\text { tive }\end{array}$ & 4.24 & 4.31 & 4.12 \\
\hline Lack of support from colleague & 4.25 & 4.67 & 4.41 \\
\hline
\end{tabular}

The mean scores were calculated on a scale from 1 (strongly disagree) to 5 (strongly agree). The barriers identified which affected the implementation of WLB initiatives in the three sectors were consistent with those of other De Cieri, Holmes, Abbott, Pettit (2005); Kirby and Krone (2002); De Cieri, Holmes, Abbott, \& Pettit, (2002) who found that communication, heavy job demands and long working hours among others were major determinants which affected the implementation of WLB programmes. The case studies provide some indicators to the major barriers to the adoption and implementation of work life balance initiatives some of which can be attributed to employee resistance to adoption of work life balance practices. Like the other can be linked to the management reluctance to adopt these policies.

In the banking industry, as banks seek to outperform one another in customer service many of the managers and employees work long work hours. However, the respondents in the educational and power sectors were not put under such pressure.

\section{CONCLUSION AND MANAGERIAL IMPLICATIONS}

This study aimed at filling the gap in literature on work life balance issues in the African continent. This article presented comparative case studies of three sectors of the Nigerian economy the study identified the (WLB) practices available in the three sectors namely Banking, Educational and the Power Sector. The various types of WLB initiatives which were available in the three sectors were explored and the barriers to implementation of the WLB initiatives were identified.

It is becoming increasingly important that Work life balance policies should be included in strategic plans of organisations. As it helps organizations gain competitive edge through been able to attract and retain individuals with the great skills and experience. The various sectors should provide a variety of flexible working pattern to help improve efficiency and effectiveness of their employees. The adoption of some work-life balance programmes would help reduce the high 
turnover rate which is currently exists within the banking sector. Although, it should be noted that specific policies may difficult to implement in various sectors hence, it is important that the sector undertakes pilot scheme to identify which policies best suits individual sectors.

The limitation to this study includes that the cross sectional nature of the study does not permit a conclusive determination of causality. However, in spite of this limitation the study still contribute to the dearth in work life balance literature in Africa continent. This study is exploratory in nature and provides a basis for further research. The purely quantitative nature of this study means that it should be tested in further qualitative research.

\section{References}

1. Abbott, J., \& De Cieri, H. (2008). Influences on work/life benefits decision making: Management and em ployee perspectives. Journal of Management and Organization, 14(3), 303322.

2. Aluko, M. E. (2008). Capital Market, Foreign Reserves Vs. Global Financial Meltdown. Nigeria: Zest International, 1(6), 1-17.

3. Bardoel, E. A., De Cieri, H., \& Shea, T. L. (2009). Measuring The Impact Of Work-Life Initiatives: The Development Of An Organisational Work-Life Performance Scale. Retrieved March 4, 2011, from http://www.ilera-directory.org/15thworldcongress/files/papers/Track_3/ Poster/CS1W_7_BARDOEL.pdf

4. Barrera, S. (2007). Work life balance "from rhetoric to reality". Retrieved February 21, 2011, from http://www.docep.wa.gov.au/WorkSafe/PDF/Forum s/worklife_balance.pdf

5. Beauregard, T. A., \& Henry, L. C. (2009). Making the link between work-life balance practices and organizational performance. Human Resource Management Review, 19 (1), 9-22. http://dx.doi.org/10.1016/j.hrmr.2008.09.001

6. CBN Statistical Bulletin (2011). Economic Diversification. Retrieved April 18, 2011, from http://www.cbn-statistical-bulletin.html

7. Chang, A., Mcdonald, P., \& Burton, P. (2010). Methodological Choices in Work-Life Balance Research 1987 To 2006: A Critical Review. The International Journal Of Human Resource Management, 21(13), 2381-2413. http://dx.doi.org/10.1080/09585192.2010.516592

8. CIA Central Intelligence World Factbook (2011). Nigeria Economy. Retrieved March 31, 2011, from https://Www.Cia.Gov/Library/Publications/The-World-Factbook/Geos/Ni.Html

9. Cresswell, J. W. (2009). Research Design - Qualitative, Quantitative, and Mixed Methods Approaches. Thousand Oaks, CA: Sage Publications, Inc.

10. De Cieri, H., \& Bardoel, E.A. (2009). What does "work-life management" mean in China and Southeast Asia for MNCs? Community, Work and Family, 12(2), 179-196. http://dx.doi. org/10.1080/13668800902778959

11. De Cieri, H., Holmes, B., Abbott, J., \& Pettit, T. (2002). Work/life balance strategies: progress and problems in Australian Organisations. Working Paper 58/02. Dept of Management, Monash University. Retrieved March 5, 2011, from http://www.agilistics.com.au/newsletter/links/ WorkLife $\% 20$ Balance $\% 20$ Stratgeies.pdf 
12. De Cieri, H., Holmes, B., Abbott, J., \& Pettit, T. (2005). Achievements and challenges for work/life balance strategies in Australian organisations. The International Journal of Human Resource Management, 16(1), 90-103.

13. Easterby-Smith, M., Thorpe, R., \& Jackson, P.R. (2008). Management Research. London: Sage Publications.

14. Hooker, H., Neathey, F., Casebourne, J., \& Munro, M. (2007). The Third Work Balance Employee Survey: Main Findings. Department of Trade and Employment Relations Research Series No. 58. London: DTI.

15. International Association of Universities (IAU) (2000). Nigeria-education system. Data for academic year: 2000-2001. Retrieved May 22, 2011, from http://www.iau.edu.ng

16. Kalliath, T., \& Brough, P. (2008). Work-Life Balance: A review of the meaning of the balance construct. Journal of Management and Organization, 1(4), 323-327.

17. Kirby, E., \& Krone, K. (2002). „The policy exists but you can’t really use it“: communication and the structuration of work-family policies'. Journal of Applied Communication Research, 30(1), 50-77.

18. National University Commission (NUC) (2009). Retrieved April 20, 2011, from http:// www.nuc.edu.ng

19. Okoro, O. I., \& Chikuni, E. (2007). Power sector reforms in Nigeria: opportunities and challenges. Journal of Power in Southern Africa, 18(3), 1-6.

20. Özbilgin, M. F., Beauregard, T. A., Tatli, A., \& Bell, M. P. (2011). Work-Life, Diversity And Intersectionality: A Critical Review And Research Agenda. International Journal Of Management Reviews, 13(2), 177-198.

21. Yin, R. K. (2003). Case Study Research: Design and Methods. Thousand Oaks, CA: Sage Publications, Inc.

\section{Contact information}

Ojo Ibiyinka Stella

Covenant University, Nigeria

Email:ibiynka.ojo@covenantuniversity.edu.ng

Salau Odunayo Paul

Covenant University, Nigeria

Email:odunayo.salau@covenantuniversity.edu.ng

Falola Hezekiah Olubusayo

Covenant University, Nigeria

Email: hezekiah.falola@covenantuniversity.edu.ng 